Elsevier

TOXLett. 1519

\title{
ACUTE NEPHROTOXICITY OF 1,1-DICHLOROETHYLENE IN THE RAT AFTER INHALATION EXPOSURE
}

(Histopathology; calcium disposition; enzyme induction)

\author{
N.M. JACKSON and R.B. CONOLLY*
}

Toxicology Program, Department of Environmental and Industrial Health, School of Public Health, The University of Michigan, Ann Arbor, MI 48109-2029 (U.S.A.)

(Received October 10th, 1985)

(Accepted October 25th, 1985)

\section{SUMMARY}

A renal toxicity of $4 \mathrm{~h}$ inhalation exposure to 1,1-dichloroethylene (vinylidene chloride; VDC) was studied in male Sprague-Dawley rats. Kidney wt./body wt. ratios, serum urea nitrogen and creatinine levels were significantly increased $24 \mathrm{~h}$ after exposure to $250 \mathrm{ppm}$ or more of VDC. Histopathologic examination by light microscopy of hematoxylin and eosin (H\&E)-stained sections revealed severe tubular necrosis with calcium deposits at the higher exposure concentrations. Specific staining for calcium oxalate was negative, indicating that biotransformation of VDC to oxalate is probably not responsible for its nephrotoxicity. Pretreatment with polychlorinated biphenyl (PCB) induced the level of renal cytochrome P-450. Phenobarbital (PBT) pretreatment did not alter the renal P-450 level, but both PCB and PBT pretreatments antagonized VDC nephrotoxicity. These pretreatments have also been reported to antagonize VDC-induced hepatotoxicity. In summary, inhalation of VDC is nephrotoxic in the rat; the mechanism of nephrotoxicity does not involve calcium oxalate formation, and the magnitude of nephrotoxicity does not correlate directly with the total amount of renal cytochrome P-450.

\section{INTRODUCTION}

VDC is primarily used in the production of methyl chloroform and thermoplastic polymers [1]. VDC has been identified as a contaminant not only in the workplace but also in the closed environments of nuclear submarines and of spacecraft [2].

Although the hepatotoxicity of VDC has been extensively studied [3] there is little information concerning its nephrotoxic effects. Chronic exposure to VDC has been reported to result in kidney and liver injury in a variety of test species $[4,5]$. Jenkins

\footnotetext{
* To whom correspondence should be addressed.
}

Abbreviations: PBT, phenobarbital; PCB, polychlorinated biphenyl; VDC, vinylidene chloride. 
and Andersen [6] examined the acute nephrotoxicity of VDC in the rat following oral administration. They observed increases in plasma urea nitrogen, plasma creatinine and kidney weights, which were potentiated by fasting for $18 \mathrm{~h} \mathrm{im-}$ mediately before VDC administration [6]. Fasting depletes glutathione (GSH) stores [7] and, since activated intermediates of VDC are detoxified by GSH [8], this depletion may be responsible for the observed potentiation of VDC nephrotoxicity. Jenkins and Andersen [6] also reported the occurrence of blue-black amorphous deposits, resembling calcium deposits, in H\&E-stained necrotic renal tubules following VDC administration. Oxalic acid has been identified in small amounts in the urine of rats exposed to VDC [9]. Calcium oxalate is a potent nephrotoxicant [10] but there have to date been no reports of investigations which specifically addressed the possibility that VDC nephrotoxicity is due to the formation of calcium oxalate.

Alteration of the oxidative metabolism of VDC with inducers and inhibitors of cytochrome P-450 is known to affect VDC hepatotoxicity [11]. Masuda and Nakayama [12] have shown in mice that carbon disulfide inhibits hepatic and renal microsomal drug-metabolizing enzyme activities and protects against renal and hepatic injury caused by VDC.

These reports and our interest in mechanisms of VDC toxicity lead us to the studies of VDC nephrotoxicity reported here. Rats were exposed to VDC by inhalation. A concentration-response curve was obtained. The role of calcium oxalate formation and the effects of PBT and PCB pretreatments were examined.

\section{METHODS}

\section{Inhalation exposures}

Inhalation exposures were performed in 30-1 glass and stainless steel dynamic chambers. 4-6 Rats were used per chamber. VDC (MEHQ-inhibited, donated by Dow Chemical Co., Midland, MI) was volatilized in a gas washing bottle by a metered air flow. Total chamber air flow was maintained at $20 \mathrm{l} / \mathrm{min}$. The actual VDC concentration was monitored by FID gas chromatography. Chamber air samples were taken at 15-min intervals with a gas-tight syringe and injected into a Varian 940 gas chromatograph with a column of $10 \%$ Carbowax 6000 on Diatoport $\mathrm{S}$ 60/80 mesh. All exposures were for $4 \mathrm{~h}$, and began between 10:00 and 12:00 a.m.

\section{Animals and pretreatments}

Male Sprague-Dawley rats (225-275 g) were housed in pairs in suspended cages, over pine chip bedding, on a 12-h light-dark cycle. Food and water were supplied ad lib. For the pretreatment studies, rats received either $60 \mathrm{mg} / \mathrm{kg} /$ day sodium PBT $(30 \mathrm{mg} / \mathrm{ml}$ in water) by gavage for 4 days, or $100 \mathrm{mg} / \mathrm{kg} / \mathrm{day}$ PCB (Aroclor 1254 , $50 \mathrm{mg} / \mathrm{ml}$ in corn oil) by gavage for 3 days. VDC exposure was on the day following the last pretreatment. All rats were fasted for $18 \mathrm{~h}$ prior to exposure and received no food or water during exposure. Rats were allowed food and water after exposure. 
Killing was by decapitation and exsanguination $24 \mathrm{~h}$ after the start of VDC exposure. For P-450 determinations, killing was $24 \mathrm{~h}$ after the last PCB or PBT pretreatment, allowing us to estimate the $\mathrm{P}-450$ level that pretreated rats had during VDC exposure.

\section{Biochemical assays}

Serum urea nitrogen ( $\mathrm{mg}$ urea nitrogen $/ 100 \mathrm{ml}$ serum) was measured by the urease method [13]. The picric acid method was used to determine serum creatinine concentrations ( $\mathrm{mg}$ creatinine $/ 100 \mathrm{ml}$ serum) [13]. Kidneys were excised and weighed for the determination of kidney wt. $/ 100 \mathrm{~g}$ body wt. ratios.

\section{Cytochrome P-450 assay}

Rats were killed $24 \mathrm{~h}$ after the last PBT or PCB pretreatment and after $18 \mathrm{~h}$ fasting. Livers and kidneys were removed and microsomes prepared according to the method of Omura and Sato [14]. Protein content was determined by the Biuret method [15]. The microsomal samples were diluted to $1 \mathrm{mg}$ protein $/ \mathrm{ml}$ for liver and to $2 \mathrm{mg}$ protein/ml for kidney. The carbon monoxide difference spectrum of reduced cytochrome P-450 was measured using an Aminco DW-2-UV-visible spectrophotometer.

\section{Statistical analyses}

Dose-response data were analyzed by 1-factor analysis of variance [16] and the effects of PCB and PBT pretreatment on cytochrome P-450 levels by 2-factor analysis of variance [16]. Multiple comparisons by the method of Bonferroni were used to establish the significance of differences at individual exposure levels $(P<0.05)$. Student's $t$-test was used to compare individual means when applicable.

\section{Histopathology}

Slices of tissue were fixed in neutral buffered formalin. Fixed tissues were infiltrated, embedded in paraffin, and sectioned. Six-micron-thick sections were staincd with either H\&E [17] or silver nitrate-safranin. The von Kossa method [18] was used to stain for total calcium and the Pizzalato method [10] was used for the specific determination of calcium oxalate.

\section{RESULTS AND DISCUSSION}

Kidney wt./body wt. ratios, serum urea nitrogen, and serum creatinine measurements were increased $24 \mathrm{~h}$ after exposure to VDC concentrations of 250 ppm or greater (Table I). Some lethality also occurred in each exposure group at $200 \mathrm{ppm}$ or more (Table I). We think that the apparent decrease in nephrotoxicity at $400 \mathrm{ppm}$ VDC may be due to more susceptible, and consequently more severely affected, animals dying before the scheduled killing. 

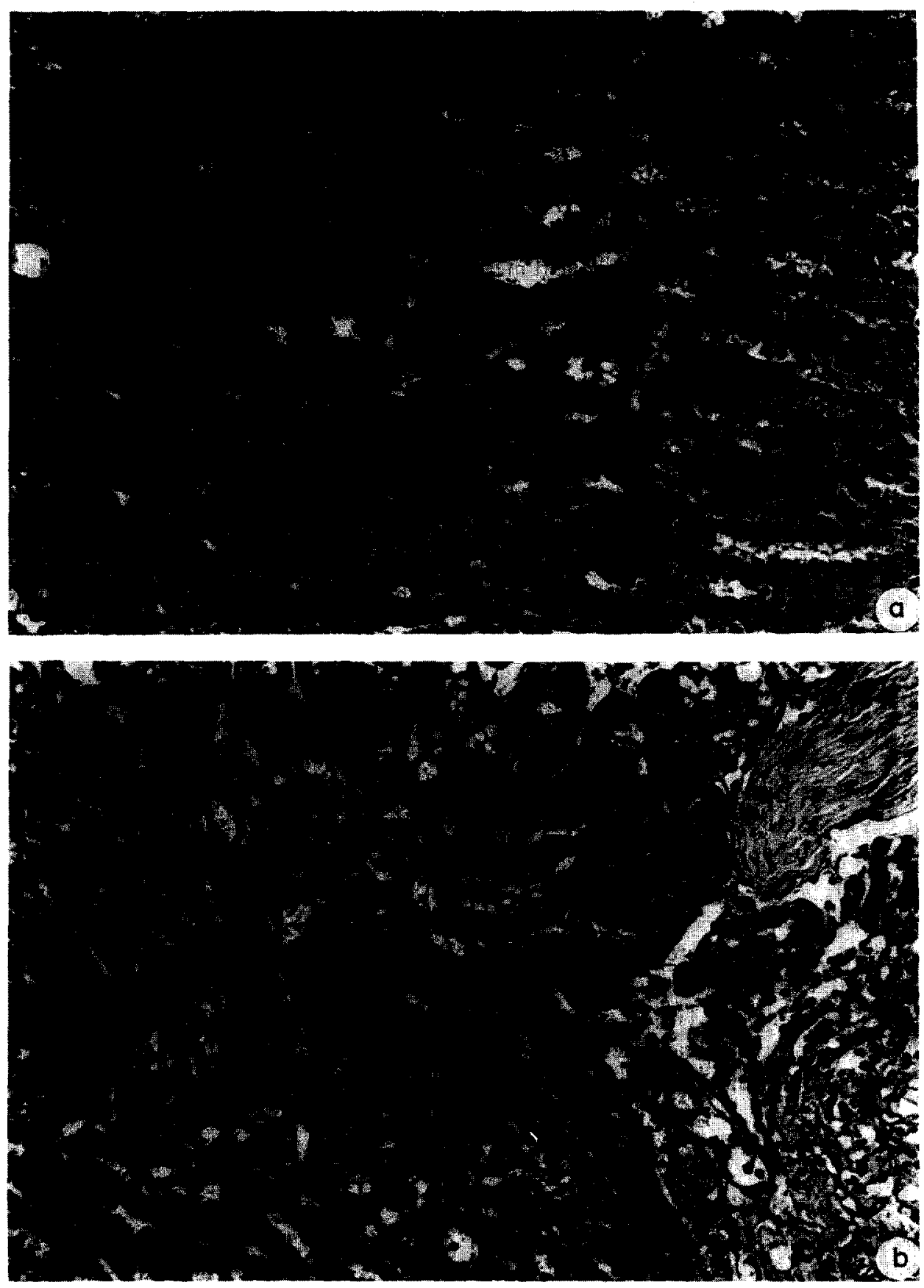

Fig. 1. Histopathological assessment of the effects of vinylidene chloride on the renal cortico-medullary junction (hematoxylin and eosin, magnification $\times 140$ ). (a) Control; (b) $250 \mathrm{ppm}$ VDC, $4 \mathrm{~h}$ exposure. Note vacuolated tubule cells in the cortex; (c) $300 \mathrm{ppm}$ VDC, $4 \mathrm{~h}$ exposure. Note necrosis of tubules and 

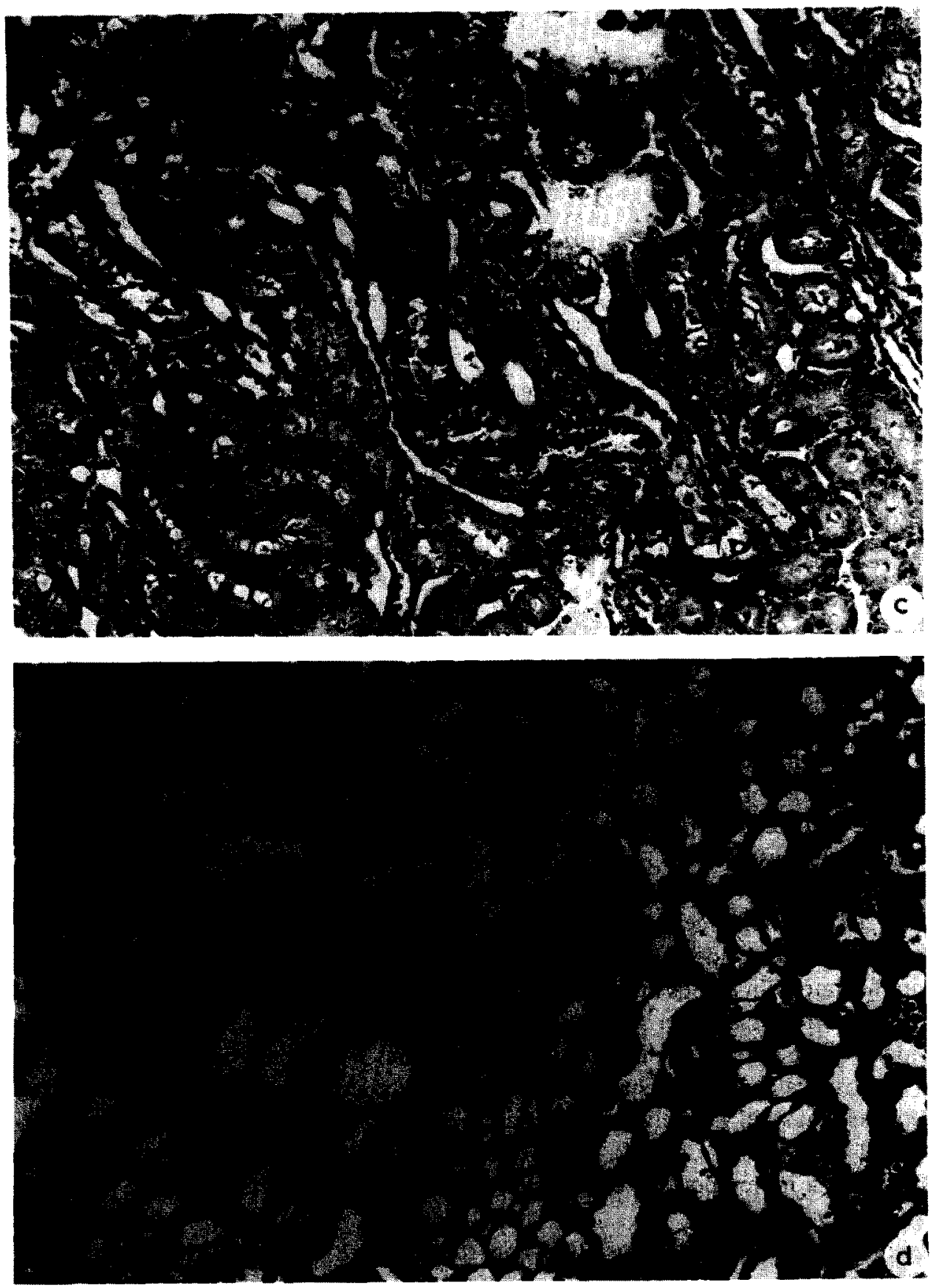

dark staining deposits in tubule cells (arrows); (d) $400 \mathrm{ppm}$ VDC, $4 \mathrm{~h}$ exposure. Note massive necrosis of tubules and dark-staining deposits (arrows). 
TABLE I

\begin{tabular}{|c|c|c|c|c|}
\hline $\begin{array}{l}\text { VDC } \\
\text { concentration }^{\mathrm{a}} \\
(\mathrm{ppm})\end{array}$ & Mortality $^{b}$ & $\begin{array}{l}\text { Kidney wt./body wt. } \\
(\mathrm{g} / 100 \mathrm{~g})\end{array}$ & $\begin{array}{l}\text { Serum urea nitrogen } \\
(\mathrm{mg} / 100 \mathrm{ml})\end{array}$ & $\begin{array}{l}\text { Serum creatinine } \\
(\mathrm{mg} / 100 \mathrm{ml})\end{array}$ \\
\hline 0 & $0 / 22$ & $0.88 \pm 0.04$ & $8.3 \pm 0.4$ & $0.66 \pm 0.02$ \\
\hline 200 & $1 / 4$ & $0.97 \pm 0.06$ & $11.0 \pm 0.2$ & $0.78 \pm 0.05$ \\
\hline 250 & $1 / 16$ & $1.42 \pm 0.09^{*}$ & $29.8 \pm 5.2^{*}$ & $1.51 \pm 0.17^{*}$ \\
\hline 300 & $3 / 14$ & $1.49 \pm 0.08^{*}$ & $41.8 \pm 5.0^{*}$ & $1.99 \pm 0.25^{*}$ \\
\hline 375 & $3 / 12$ & $1.40 \pm 0.13^{*}$ & $33.2 \pm 7.5^{*}$ & $1.55 \pm 0.39^{*}$ \\
\hline 400 & $3 / 6$ & $1.49 \pm 0.20^{*}$ & $22.8 \pm 9.1^{*}$ & $1.15 \pm 0.32^{*}$ \\
\hline
\end{tabular}

Male Sprague-Dawley rats were killed $24 \mathrm{~h}$ after the start of a 4-h inhalation exposure to various concentrations of VDC. Data are expressed as mean \pm SEM.

a Actual chamber concentration varied by less than $5 \%$ of nominal concentration during exposure.

${ }^{b}$ Mortality data are presented as no. dead before sacrifice/total no. exposed).

* Significantly different from control $(P \leqslant 0.05)$ by one-factor analysis of variance with multiple comparisons by the method of Bonferroni.

VDC exposure also caused histopathological changes in the kidney. For reference, a section from a control kidney is shown in Fig. 1a. A typical section prepared after exposure to $250 \mathrm{ppm}$ VDC for $4 \mathrm{~h}$ shows only moderate cellular swelling in the renal cortex (Fig. 1b). Exposure to higher concentrations of VDC (>300 ppm) resulted in dark-staining deposits, resembling calcium salts, within the tubule cells (Fig. 1c), and in severe cortical tubular necrosis (Fig. 1d).

Since oxalate is a urinary metabolite of VDC [9], the possibility that calcium oxalate is the cause of VDC-induced nephrotoxicity was examined. Sections of renal tissue containing blue-black deposits after hematoxylin and eosin staining were analyzed for birefringence by light microscopy using a polarizing filter. No birefringence was seen. Under identical conditions, actual calcium oxalate crystals stained with hematoxylin and eosin and were clearly birefringent. Staining for total calcium by the von Kossa silver nitrate method [16] demonstrated that the blue-black deposits were in fact calcium salts. Similar sections were treated with $2 \mathrm{~N}$ acetic acid to remove calcium phosphate and calcium carbonate salts [10]. Any remaining deposits that stain with silver nitrate must be calcium oxalate. No such silver nitratestained deposits were found. These results indicate that calcium oxalate does not constitute a major portion of the calcium deposits in the kidney following VDC exposure.

Pretreatment with PBT or PCB had the expected effects $[19,20]$ on rat liver hepatic and renal microsomal cytochrome P-450 (Table II). In the liver, PBT and PCB caused 2-fold and 3-fold increases, respectively, in the level of cytochrome P-450. PBT did not significantly alter renal cytochrome P-450, whereas $\mathrm{PCB}$ resulted in 2-fold induction. Despite this difference in hepatic and renal cytochrome 
TABLE II

EFFECT OF PBT AND PCB PRETREATMENTS ON CYTOCHROME P-450 CONTENT

\begin{tabular}{lll}
\hline Pretreatment & Liver $^{\mathrm{a}}$ & Kidney $^{\mathrm{a}}$ \\
\hline None & $100 \pm 5.5$ & $100 \pm 13$ \\
PBT & $210 \pm 9^{*}$ & $131 \pm 21$ \\
PCB & $296 \pm 4^{*}$ & $223 \pm 38^{*}$ \\
\hline
\end{tabular}

Rats were pretreated with PBT or Aroclor 1254 (PCB) and microsomal cytochrome P-450 content was measured as described in METHODS.

${ }^{a}$ Data in PBT and PCB-pretreated groups are expressed as \% of non-pretreated control \pm SEM. $N \geqslant 4$. For liver, control $=0.787 \pm 0.021 \mathrm{nmol} \mathrm{P}-450 / \mathrm{mg}$ microsomal protein; for kidney, control $=0.110$ $\pm 0.015 \mathrm{nmol} P-450 / \mathrm{mg}$ microsomal protein.

* Significantly greater than control $(P \leqslant 0.05)$ by Student's $t$-test.

P-450 induction, both pretreatments were equally effective in reducing VDC-related nephrotoxicity (Table II). These effects of PCB and PBT pretreatment on VDC nephrotoxicity parallels that shown previously for VDC hepatotoxicity [11] and is consistent with several different possible mechanisms: (a) PBT and PCB may increase hepatic metabolism of VDC causing reduced circulating VDC concentrations and correspondingly reduced accumulation of toxic metabolites in the kidney; (b) although PBT did not significantly induce total renal P-450 (Table II), levels of the P-450 isozyme(s) primarily responsible for VDC detoxification [21] may be increased; (c) PBT and PCB alter the activities of other enzyme systems, including glutathione $S$-transferase $[22,23]$. Since glutathione $S$-transferase is important for the detoxification of VDC [7], its induction by PBT and PCB could explain their antagonism of VDC nephrotoxicity.

\section{TABLE III}

EFFECT OF PRETREATMENT WITH PBT OR PCB ON THE NEPHROTOXICITY OF VDC

\begin{tabular}{lcllcl}
\hline Pretreatment & $N$ & $\begin{array}{l}\text { VDC } \\
\text { concentration } \\
(\mathrm{ppm})\end{array}$ & $\begin{array}{l}\text { Kidney wt. } \\
\text { body wt. } \\
(\mathrm{g} / 100 \mathrm{~g})\end{array}$ & $\begin{array}{l}\text { Serum urea nitrogen } \\
(\mathrm{mg} / 100 \mathrm{ml})\end{array}$ & $\begin{array}{l}\text { Serum creatinine } \\
(\mathrm{mg} / 100 \mathrm{ml})\end{array}$ \\
\hline None & 22 & None & $0.88 \pm 0.04$ & $8.3 \pm 0.4$ & $0.66 \pm 0.02$ \\
None & 11 & 300 & $1.49 \pm 0.08^{* *}$ & $41.8 \pm 5.0^{* *}$ & $1.99 \pm 0.25^{* *}$ \\
PBT & 6 & None & $0.81 \pm 0.01$ & $7.6 \pm 0.4$ & $0.89 \pm 0.03$ \\
PBT & 5 & 300 & $0.91 \pm 0.03^{*}$ & $11.5 \pm 0.7^{*}$ & $0.90 \pm 0.02^{*}$ \\
PCB & 4 & None & $1.04 \pm 0.05$ & $9.1 \pm 0.05$ & $0.53 \pm 0.01$ \\
PCB & 6 & 300 & $0.99 \pm 0.05^{*}$ & $8.2 \pm 0.3^{*}$ & $0.69 \pm 0.04^{*}$ \\
\hline
\end{tabular}

Male Sprague-Dawley rats were pretreated and exposed as described in Methods. Data are expressed as mean \pm standard error.

** Significantly greater than not exposed, identically pretreated control $P \leqslant 0.05$ by 2 -factor ANOVA with multiple comparisons by the method of Scheffe.

* Significantly less than not pretreated, similarly exposed group. $P \leqslant 0.05$ by 2 -factor ANOVA with multiple comparisons by the method of Scheffe. 
In summary, these studies show that VDC is acutely nephrotoxic in the rat after inhalation exposure. VDC nephrotoxicity does not appear to be due to the biotransformation of VDC to calcium oxalate. The similar effects of PBT and PCB pretreatments on both the hepatotoxicity and nephrotoxicity of VDC are consistent with a common mechanism of action of VDC on both of these target organs. The antagonism of VDC nephrotoxicity by PBT shows that the magnitude of this nephrotoxicity is not strictly correlated with the overall level of renal P-450.

\section{ACKNOWLEDGEMENT}

The authors would like to thank Dr. Robert Gray for his help with the detection of birefringence.

\section{REFERENCES}

1 N.I.O.S.H., Current Intelligence Bultetin, Vinyl halides carcinogenicity, Joint Publication NIOSH/OSHA 79-102, 1978.

2 T.J. Haley, Vinylidene chloride: a review of the literature, Clin. Toxicol. 8 (1975) 633-643.

3 E.P.A. Vinylidene chloride: health and environmental impacts. EPA Office of Toxic Substances 560/6-76-023, 1976.

4 D.D. Irish, Halogenated hydrocarbons: 1. Aliphatic. in F.A. Patty, (Ed.), Industrial Hygiene and Toxicology, Vol. II, Wiley, New York, 1963, pp. 1241-1332.

5 J.A. Pendergast, R.A. Jones, L.J. Jenkins, and J. Siegal, Effects on experimental animals of long term inhalation of trichloroethylene, carbon tetrachloride, 1,1,1-trichloroethane, dichlorodifluoromethane and 1,1-dichloroethylene, Toxicol. Appl. Pharmacol., 10 (1967) 270-289.

6 L.J. Jenkins, and M.E. Andersen, 1,1-Dichloroethylene nephrotoxicity in the rat, Toxicol. Appl. Pharmacol., 46 (1978) 131-141.

7 R.J. Jaeger, R.B. Conolly, and S.D. Murphy, Effect of 18 -h fast and glutathione depletion on 1,1-dichloroethylene-induced hepatotoxicity and lethality in rats, Exp. Mol. Pathol.. 20 (1974) $187-198$.

8 D. Reichert, H.W. Weiner, M. Metzler, and D. Henschler, Molecular mechanism of 1,1-dichloroethylene toxicity, excreted metabolites reveal different pathways of reactive intermediates. Arch. Toxicol., 42 (1979) 159-169.

9 B.K. Jones, and D.E. Hathway, The biological fate of vinylidene chloride in rats, Chem.-Biol. Interact., 20 (1978) $27-51$.

$10 \mathrm{P}$. Pizzalato, Histochemical recognition of calcium oxalate, J. Histochem. Cytochem., 12 (1964) 333-336.

11 E.S. Reynolds, M.T. Moslen, S. Szabo, R.J. Jaeger, and S.D. Murphy, Hepatotoxicity of vinyl chloride and 1,1-dichlorocthylenc, Am. J. Pathol., 81 (1975) 219-236.

12 Y. Masuda, and N. Nakayama, Protective action of diethyldithiocarbamate and carbon disulfide against acute toxicities induced by 1,1-dichloroethylene in mice, Toxicol. Appl. Pharmacol., 71 (1983) 42-53.

13 N.W. Teitz, in Fundamentals of Clinical Chemistry, 2nd ed., W.B. Saunders, Philadelphia, 1976, pp. 991-999.

$14 \mathrm{~T}$. Omura, and R. Sato, The carbon monoxide-binding pigment of liver microsomes, 1 . Evidence for its hemoprotein nature. J. Biol. Chem., 239 (1964) 2370-2378. 
15 A.G. Gornall, C.J. Bardawill, and M.M. David, Determination of serum proteins by means of the Biuret reaction, J. Biol. Chem., 177 (1949) 751-766.

16 J. Netter and W. Wasserman, Applied Linear Statistical Models, Richard D. Irwin, Homewood, IL, 1974.

17 A. Preece, Manual for Histopathology Technicians, 2nd ed., Little Brown, Boston, 1959.

18 A.G.E. Pearse, Histochemistry: theoretical and applied, 3rd ed., Little Brown, Boston, 1972.

19 C.L. Litterst, E.G. Minmaugh, and T.E. Grum, Comparative alterations extrahepatic drug metabolism by factors known to affect hepatic activity, Biochem. Pharmacol., 26 (1977) 749-755.

20 W.M. Kluwe and J.B. Hook, Metabolic activation of nephrotoxic haloalkanes, Fed. Proc., 39 (1980) 3129-3133.

21 D.C. Leibler and F.P. Guengerich, Olefin oxidation by cytochrome P-450: evidence for group migration in catalytic intermediates formed with vinylidene chloride and trans-1-phenyl-1-butene, Biochemistry, (1983) 5482-5489.

22 A.J. Boars, M. Jensen and D.D. Breiner, The influence of phenobarbital, 3-methylcholanthrene and 2,3,7,8-tetrachlorodibenzo- $p$-dioxin on glutathione $S$-transferase activity in rat liver cytosol, Biochem. Pharmacol., 27 (1978) 2487-2494.

23 M. Ahotupa, Enhancement of epoxide-metabolizing enzyme activities by pure PCB isomers, Biochem. Pharmacol., 30 (1981) 1866-1869.

24 M.E. Andersen and L.J. Jenkins, Oral toxicity of 1,1-dichloroethylene in the rat: effects of sex, age and fasting, Environ. Health. Perspect, 21 (1977) 157-163.

25 M.E. Andersen, M.L. Gargas, R.A. Jones and L.J. Jenkins, The use of inhalation techniques to assess the kinetic constants of 1,1-dichloroethylene metabolism, Toxicol. Appl. Pharmacol., 47 (1979) 395-409. 